\title{
O SEXO E O CORPO COMO VEÍCULOS DAS PRÁTICAS MÁGICAS NO ESOTERISMO DO SÉCULO XX: REFLEXÕES SOBRE MAGIA SEXUAL EM THELEMA
}

Beatriz PARISI ${ }^{1}$

RESUMO: O presente artigo tem como objetivo demonstrar a importância da magia sexual na construção de uma forma específica de corporalidade dentro das práticas esotéricas do século XX, utilizando como estudo de caso a Thelema, sistema mágicoreligioso desenvolvido por Aleister Crowley. O corpo, através da ressignificação das práticas sexuais e de seu espaço na vida social, ganha centralidade como locus da experiência vivida e como potência de transformação ativa de si e do mundo. Essa nova forma de construir o corpo, positivando-o como o espaço da subjetividade e da plasticidade, está totalmente inserido nas demandas sociopolíticas do fin-de-siècle. Investigar-se-á essa forma de se construir o corpo com recurso a um aparato míticoritual que reforça, através da repetição do rito, esse novo corpus de valores atrelados a categorias já existentes, com ênfase ao sexo, mostrando uma outra face da dualidade discursiva fundante da modernidade: o corpo como duplo do sujeito (LE BRETON, 2002[1990]).

PALAVRAS-CHAVE: Magia. Esoterismo. Thelema. Corpo. Antropologia.

\footnotetext{
1 Universidade Federal de São Paulo (Unifesp), Escola de Filosofia, Letras e Ciências Humanas, Guarulhos - SP Brasil. Mestranda em Ciências Sociais. ORCID: https://orcid.org/0000-0002-8103-0767. biiaparisi@outlook.com.
} 


\section{THE SEX AND THE BODY AS VEHICLES OF MAGICAL PRACTICES ON TWENTIETH CENTURY'S ESOTERICISM: REFLECTING UPON SEX MAGIC ON THELEMA}

ABSTRACT: This article aims to demonstrate the importance of sex magic in the construction of a specific form of corporeality within the esoteric practices of the 20th century, using Thelema, a magical-religious system developed by Aleister Crowley, as a case study. The body, through the re-signification of sexual practices and their space in social life, gains centrality as a locus of lived experience and as a potential for active transformation of itself and the world. This new way of building the body, positifying it as the space of subjectivity and plasticity, is totally inserted in the socio-political demands of the fin-desiècle. This way of building the body will be investigated using a mythical-ritual apparatus that reinforces, through the repetition of the rite, this new corpus of values linked to already existing categories, with an emphasis on sex, showing another face of foundational discursive duality of modernity: the body as a double of the subject (LE BRETON, 2002 [1990]).

KEYWORDS: Magic. Esotericism. Thelema. Body. Anthropology.

\section{Introdução}

Quando se fala em Esoterismo, a imagem que geralmente nos vem à mente é aquela na qual membros de dada religiosidade vivem em comunidade com um líder messiânico e cujas práticas giram em torno de religiôes orientais, como o Hinduísmo e o Budismo, e em uma postura de positividade frente à vida. Outro cenário possível é aquele em que diversas pessoas estáo reunidas em um "culto satânico", com direito à sacrifício de mulheres e animais, com roupas escuras e em um ambiente amedrontador. A questáo colocada por esses estereótipos é coerente com um processo histórico de exclusão e deslegitimação da magia frente à religião e à ciência (HANEGRAAFF, 2012; THOMAS, 1971) que data do século XVI, com a Reforma Protestante, por conta do processo de racionalização das esferas de ação (WEBER, 2016[1920]).

Levando em consideração que, no século XIX, novas articulações entre essas três esferas foram possibilitadas - por um lado, pelo humus cultural da época na Europa; por outro, pela produção de uma literatura de cunho orientalista, que voltava-se à sistematizaçáo das experiências de certos estudiosos e viajantes nas colônias imperiais europeias ao público euro-americano e à criação de um 
imaginário sobre o Oriente - e o aparecimento notório de diversas religiosidades esotéricas na segunda metade desse século - conhecidas dentro do espectro dos "novos movimentos religiosos" (GUERRIERO, 2016) -, fica claro que a magia, por mais que tenha sido colocada como centro das práticas das religióes que surgem no período, não perde seu caráter social de "irracionalidade", de uma prática assentada em "princípios absurdos" - que não condizem com a racionalidade típica de uma sociedade industrial que justifica seus feitos por meio de um discurso de progresso, calcado na ciência positivista. Assim, todas as religiosidades cujos cernes gravitam em torno da magia não são levadas a sério; são deslegitimadas e colocadas em posição marginalizada perante as religióes mais "tradicionais". Tais práticas mal são consideradas enquanto "religiosas", indicando que a categoria "magia" é algo maldito, ridículo, ilegítimo, primitivo.

Outra forma de se abordar a questão é através de uma peculiaridade do Esoterismo do século XX: a centralidade da magia sexual nas correntes esotéricas, principalmente àquelas denominadas ocultistas, e a consequente importância e positivação do corpo para a realização das práticas mágicas. Não se quer dizer aqui que a magia sexual não existia anteriormente ao século $\mathrm{XX}$, mas ela toma contornos muito distintos neste, como será visto adiante. O que é importante apreender no momento é que o sexo como prática mágica está intimamente ligado às demandas sociais e aos discursos construídos acerca da sexualidade a partir do século XIX (FOUCAULT, 2015[1976]; URBAN, 2006), que culminam nos movimentos contraculturais na Europa e Estados Unidos a partir da década de 1960. Ademais, colocar o sexo como centro de uma prática mágica, mesmo que marginalizada socialmente, nos mostra a necessidade do corpo enquanto instância material para a realização de uma operação mágica e como locus de novas formas de apreensão e organização do mundo, este reorientado pelos discursos produzidos e, sobretudo, pela prática - condizentes com uma prática discursiva moderna de positivação e estetização do corpo (LE BRETON, 2002[1990]). Isso porque o Esoterismo no Ocidente se caracteriza, por um lado, por uma apropriação e ressignificação de discursos e práticas que já existiam dentro de outras religióes ou estruturas discursivas - dando ênfase à apropriação de religiôes orientais (DJURDJEVIC, 2014a; URBAN, 2006) -, fazendo com que a combinação entre esses elementos destradicionalizados (HEELAS, 1993) forme um conjunto prático-discursivo distinto; por outro, há a restituição de uma "tradição esotérica única", calcada na ideia de "sabedoria ancestral" (HANEGRAAFF, 2012), que coloca todas as práticas esotéricas em um arranjo histórico no qual uma é a sucessão da outra, tendo por início, de maneira geral, Hermes Trismegisto (YATES, 1995[1964]). 
Dito isso, o propósito deste artigo é refletir sobre a importância da magia sexual no Esoterismo do século XX e sua centralidade para a ressignificaçáo de uma concepção de corpo no Ocidente, muito enraizada, por um lado, em princípios morais cristãos, que reduzem a sexualidade à questão da procriação, e no qual o corpo é construído de forma a negar a si (MARTINS apud CAROZZI et al., 1999); por outro, em uma dualidade instaurada pelo racionalismo derivado do desenvolvimento de uma ciência mecanicista e de um discurso filosófico cartesiano que separa o homem de seu corpo, reduzindo este a uma máquina que precisa ser aperfeiçoada e silenciada em suas manifestaçóes (LE BRETON, 2002[1990]). Para tal, utilizarei como estudo de caso Thelema, sistema mágico-religioso desenvolvido por Aleister Crowley em 1904, por conta de sua importância na sistematização da magia sexual e por delinear os contornos do Esoterismo no século XX. Dividirei tal reflexão em algumas partes: primeiro, tratarei de Thelema, explicando brevemente sua cosmologia e seu aparato teórico-prático; em segundo lugar, falarei sobre a magia sexual no Ocidente, utilizando-me de aporte antropológico-historiográfico para demonstrar a peculiaridade desta no século XX; feito isso, articularei os contornos da magia sexual no contexto em questão com a apropriação e ressignificação de práticas orientais no Ocidente, como a Yoga e o Tantra; por fim, demonstrarei a importância das práticas thelêmicas de alteração de consciência, que incluem magia sexual, para uma construção e ressignificação do corpo dentro de uma perspectiva antropológica. Oferecerei um caminho interpretativo a partir das ideias de crise de presença e reintegração religiosa, propostas por Ernesto de Martino (2004[1948], 2012[1956]).

Mas a indagação que proponho é esta: Qual a importância da magia sexual para o entendimento dos novos movimentos religiosos? A resposta reside na questão do corpo, na ressignificação do estar no mundo (DE MARTINO, 1977, 2004[1948], 2012[1956]; LE BRETON, 2002[1990]), que não se dá apenas no plano simbólico (LÉVI-STRAUSS, 2012), mas também no âmbito da práxis (STENGERS, 2008).

\section{Thelema}

Também conhecida por Corrente 93, Thelema² denomina o sistema filosófico-mágico-religioso desenvolvido por Aleister Crowley ${ }^{3}$ (1875-1947) a

\footnotetext{
Thelema é a palavra grega para "Vontade".

3 Poeta e um dos maiores nomes do Ocultismo do século XX, Crowley nasce em 1875, em uma família de protestantes, extremamente religiosa, o que lhe gerou uma relação conflituosa com o Cristianismo, que está refletida
} 
partir de 1904, ano que demarca o "recebimento" do Livro da Lei ${ }^{4}$ por ele, que é o livro sagrado aos thelemitas e que traça uma conduta específica frente à vida baseada na ideia de Vontade. Apesar de não haver uma concepção monoteísta de Deus neste sistema religioso, ou mesmo uma "ideia" de deus que seja exterior ao indivíduo, há deuses em Thelema, sendo os principais: Nuit, Hadit e Heru$\mathrm{Ra}-\mathrm{Ha}$, divindades de origem egípcia que são "repensadas" neste contexto. Nuit representa o imanifesto, o infinito, sendo Hadit seu consorte, que representa a individualidade. Heru-Ra-Ha é uma entidade dual composta por Ra-hoor-khuit ou Hórus e por Hoor-paar-kraat ou Set/Harpócrates, representando os aspectos ativos e passivos do ser humano que, quando unificados, "divinizam" o homem. Thelema compreende uma série de outros deuses que não somente restritos ao panteão egípcio, tanto em sua formulação por Crowley quanto por outros magistas, como Kenneth Grant. Mas é importante ressaltar a importância dada, pelo menos no plano discursivo, às divindades femininas em Thelema, principalmente Babalon, que é a Prostituta Sagrada, manifestação "material" de Nuit, sendo o princípio feminino do Universo, em relação de complementariedade com a Besta Solar 666, que é o princípio masculino do Universo - note que esta formulação discursiva, retirada do Apocalipse bíblico e claramente ressignificada, será importante na prática mágica sexual thelêmica.

Como vimos acima, a narrativa thelêmica que justifica sua necessidade de estar no mundo está ancorada, sobretudo, em uma reinterpretação da mitologia egípcia: o tempo está dividido em Aeons ou Eras, cada uma correspondendo a uma divindade cujos atributos definem as características de cada Aeon. Essa divisão varia de acordo com qual vertente de Thelema estamos nos referindo, mas acreditamos que indicar a versão de Crowley seja suficiente no momento 5 . Os Aeons seguem de forma linear: o de Ísis, Osíris, Hórus e Maat. Crowley sustenta que o recebimento do Livro da Lei denotou uma mudança do Aeon de

em seu percurso mágico. Inicia-se, em 1898, na Ordem Hermética da Aurora Dourada, tendo um desenvolvimento notório e entrando em contato com práticas orientais, mas é expulso em 1902, entrando em um período de ceticismo mágico, que perdura até 1904, com o recebimento do Livro da Lei. Em 1907, funda a Astrum Argentum, ordem iniciática que serve à prática da mágicka e da Lei de Thelema e, em 1910, entra na Ordo Templi Orientis (O.T.O.), ordem de origem pseudo-maçônica que é convertida à Lei de Thelema em 1919. Em 1920, funda a Abadia de Thelema em Cefalù, na Sicília, Itália, fato que causou muita controvérsia e o fez ser expulso do país em 1923. Crowley assume a liderança da O.T.O. em 1925 e continua publicando livros e instruções para seus seguidores como profeta do Aeon de Hórus. Morre em 1947.

4 Crowley recebe tal livro durante três dias por meio de sua esposa na época, Rose Edith Kelly, que entrava em uma espécie de transe. Ele credita a transmissão a Aiwass, uma entidade extraterrestre ligada ao par Set-Hórus, fundamentais no novo Aeon, visto adiante.

5 A ideia de Aeon sustentada por Kenneth Grant (1980), da vertente tifoniana de Thelema, não é linear. Os Aeons de Hórus e de Maat, este que estaria por vir, acontecem ao mesmo tempo porque estão fora do espaço-tempo. Percebe-se a influência das teorias da física quântica nos sistemas mágicos esotéricos. 
Osíris - preso ao auto sacrifício e às religióes monoteístas e "opressoras" - ao Aeon de Hórus, que exigiria uma outra forma de se relacionar com o mundo, principalmente pela destruição das religióes "opressoras" do passado - isso, a nosso ver, toca profundamente a dimensão corporal. A Lei de Thelema seria o resumo desta nova postura: "Faze o que tu queres, há de ser o todo da Lei" (AL I, CROWLEY, 2017[1904], \$40).

Quando nos deparamos com a Lei de Thelema, fica muito clara a ideia do Aeon de Hórus: um momento histórico baseado na afirmação da liberdade individual e da preeminência do indivíduo frente às "amarras sociais". Isso fica ainda mais evidente quando olhamos para outro postulado fundamental: "Todo homem e toda mulher é uma estrela” (AL I, CROWLEY, 2017[1904], \$3). É a legitimação de que cada pessoa aporta um universo distinto, um conjunto específico de significados atribuídos à ação, uma subjetividade que se afirma na diferença para com o outro. Contudo, não podemos entender tais postulados se não apreendermos aquilo que as costura: a noção de Vontade. Esta é entendida como um conjunto comum a todos os indivíduos de disposiçóes específicas a cada um deles. Em outras palavras, pode-se relacionar tal conceito com o de self - termo muito comum quando nos referimos às religióes de cunho esotérico, cujo enfoque se dá no aprimoramento do "Eu" a partir de práticas que, no fundo, cultuam o "Eu" (HEELAS, 1993) -, que indicaria aquele espaço no qual a subjetividade jaz intacta, para além de uma personalidade "afetada" pela sociedade, entendida por Ego. O objetivo do thelemita é entender a sua Vontade e persegui-la sem metas a serem alcançadas. De acordo com Gordan Djurdjevic (2008), o self é mais um verbo do que um substantivo devido à ênfase dada à dimensão da ação individual na construção deste, já que o selfé um transformar-se sem objetivos para quem consegue encontrar sua Vontade em meio ao caos do Ego - da cultura.

Essa "busca para dentro" para encontro com a Vontade se dá por meio da mágicka, "forma de teoria e prática que envolve as tradiçôes esotéricas ocidental e oriental através da orientação ideológica do Livro da Lei e da Lei de Thelema" (DJUDJEVIC, 2008, p.2, tradução nossa ${ }^{7}$ ). Crowley define a mágicka como

\footnotetext{
6 Comumente se referenda O Livro da Lei por AL, já que é uma abreviatura de Liber Al Vel Legis, AL significando Deus. O livro é composto por três capítulos, cada qual sendo "narrado" por uma das divindades da Trindade Thelêmica - Nuit, Hadit e Ra-hoor-khuit (Set e Hórus). Desta maneira, coloca-se na referência o número do capítulo para que a divindade que transmitiu tais palavras seja identificada. Por fim, o número referendado não diz respeito à página, mas ao aforismo no qual tal citação está contida.

7 “In Crowley's reinterpretation, Magick is a form of theory and practice, which embraces both Eastern and Western esoteric traditions, infused by the dominant ideological orientation anchored in the message of The Book of the Law and the Law of Thelema." (DJURDJEVIC, 2008, p.2).
} 
"a ciência e a arte de causar transformaçóes em conformidade com a Vontade" (CROWLEY, 2017, p.7, tradução nossa ${ }^{8}$ ). A mágicka será explorada na seção seguinte. Entretanto, é de importância ressaltar que Thelema não é um sistema "fechado": está sempre em transformação; há sempre algo sendo adicionado, repensado, dependendo de quem se apropria dele. Por ser uma religião que se constituiu através de instruçóes sobretudo escritas - Crowley transmitia seu sistema via manuscritos dentro das ordens iniciáticas que comandava -, esses materiais ficaram restritos durante muito tempo aos Adeptos. Todavia, com a internet e a consequente expansão de informaçôes, esses materiais foram divulgados e são encontrados com mais facilidade, mas alguns ainda estão circunscritos aos iniciados em Thelema. A isto soma-se a questão de que Thelema se "popularizou" após a morte de Crowley, durante o movimento da Nova Era, acredita-se pela apropriação política da figura de Crowley e mesmo pelas afinidades deste sistema com o período. Mas o perfil dos adeptos seguiu mais ou menos o mesmo: camadas médias altamente escolarizadas, com destaque aos artistas de ordem diversa.

Feita essa introdução brevíssima à cosmologia thelêmica, discutamos a questão da magia sexual em perspectiva histórico-antropológica a fim de apreendermos a singularidade que esta toma no século XX, novamente tomando Thelema como exemplo profícuo.

\section{Magia sexual e sexualidade: uma perspectiva histórico-antropológica}

Como já foi dito, a magia sexual não surge no Ocidente apenas no século $\mathrm{XX}$ : o uso ritual do sexo foi utilizado por muitas comunidades religiosas, segundo certa historiografia sobre o tema (HANEGRAAFF; KRIPAL, 2008; URBAN, 2006). Mesmo esta sendo incipiente, podemos ter uma noção da relação entre sexo e corpo dentro do escopo da religião no Ocidente, que é importante para a nossa investigação.

O uso do sexo como instrumento para união mística com Deus ou para obtenção de gnose ${ }^{9}$ é algo recorrente nas religiosidades ocidentais, mas, geralmente, há uma perspectiva negativa do corpo e da sexualidade contida nelas,

\footnotetext{
8 "Magick is the Science and Art of causing Change to occur in conformity with Will." (CROWLEY, 2017, p.7).

9 Entendemos por gnose, em linhas generalíssimas, a tentativa de obtenção, por meios diversos, de conhecimento específico de outras formas de organizar e entender o mundo ou mesmo outras realidades possíveis, o que perpassa a dimensão corporal. É a busca por algo interno ou externo ao indivíduo, dependendo do contexto. É uma relação de alteridade. Geralmente envolve práticas de alteração de consciência, o que exige um método para obtenção de gnose. Ressaltamos que esta é uma formulação da própria autora sobre o conceito de gnose, uma vez que ela considera insuficientes as conceituações correntes sobre o termo (VAN DER BROEK et al., 1998), que limitam a gnose a um conhecimento especulativo de Deus, este informado, na maioria das vezes, como entidade objetiva e transcendente. Em suma, é um ensaio de conceituação antropológica sobre o termo.
} 
que estão em consonância com as noções de negação da vida mundana, de pecado e da separação entre corpo e alma, típicas da cosmovisão cristã e, posteriormente, de uma dualidade fundante da modernidade ${ }^{10}$, promovida pelo racionalismo científico e pelo pensamento cartesiano (LATOUR, 1994; LE BRETON, 2002[1990]). Podemos citar vários exemplos de práticas sexuais contemplativas ao longo da História ocidental, tais como: os Valentinianos, pertencentes ao Gnosticismo Cristão a partir do século IV d.C., com a prática do Bridal Chamber, em que os membros se casavam espiritualmente para gerar crianças superiores, mais propensas à salvação divina (DeCONICK apud HANEGRAAFF; KRIPAL, 2008; URBAN, 2006); ou a comunidade gnóstica dos Borboritas ${ }^{11}$ (séculos IV-VI d.C.), que possuía uma visão diferenciada do corpo e da sexualidade quando relacionados à glorificação de Deus. $\mathrm{O}$ ato sexual era visto como uma forma de sofrimento semelhante à de Jesus quando foi crucificado. Assim, o elemento "divino" está localizado no poder de procriação e a salvação se encontra na emissão de fluidos sexuais, que são oferecidos a Deus e consumidos no rito de Eucaristia.

Fazendo uma breve digressão sobre sexualidade, na Inglaterra do século XIX, durante a Era Vitoriana- permitam-nos o salto histórico -, falava-se muito sobre sexo (FOUCAULT, 2015 [1976]), fato que remonta ao século anterior:

Entretanto, por volta do século XVIII nasce uma incitação política, econômica, técnica, a falar do sexo. E não tanto sob a forma de uma teoria geral da sexualidade, mas sob forma de análise, de contabilidade, de classificação e de especificação, através de pesquisas quantitativas ou causais. Levar 'em conta' o sexo, formular sobre ele um discurso que não seja unicamente o da moral, mas da racionalidade, eis uma necessidade suficientemente nova para, no início, surpreender-se consigo mesma e procurar desculpar-se (FOUCAULT, 2015 [1976], p. 26).

Logo, constrói-se um discurso científico voltado à classificação das formas de sexualidade e da patologização de suas formas aberrantes, estas aliadas a um "silêncio social" sobre o sexo. Porém, se olharmos para uma perspectiva teórica para além da proposta por Foucault (2015 [1976]), compreendendo a sexualida-

\footnotetext{
${ }^{10}$ Partilhamos da concepção de Latour (1994) sobre a modernidade, na qual ela é entendida enquanto dispositivo de classificação da realidade no Ocidente a partir do século XVII com a separação radical entre natureza e cultura, operando sempre a partir de dualidades "purificadas".

${ }^{11}$ O termo "borborita" significa "imundo", o que denota uma classificação pejorativa de outros perante esta comunidade, provavelmente devido às suas concepções de corpo e sexualidade, que iam à contrapelo do discurso dominante no Ocidente, o cristão. Ver Van Der Broek (apud HANEGRAAFF; KRIPAL, 2008).
} 
de também como um conjunto de práticas socialmente estabelecidas (WEEKS, 2012[1981]), percebemos que essa prática discursiva sobre o sexo atinge principalmente as camadas médias da sociedade inglesa e é uma resposta institucional aos "excessos" das classes populares; é uma forma de controle e regulação da vida social por meio da sexualidade, definindo os parâmetros socialmente aceitos da conduta sexual. Assim, há uma forma de repressão à sexualidade no período em questão, mas não somente no que diz respeito a um argumento religioso: é um poder institucionalizado que cataloga, controla e regula a vida social, sendo a sexualidade uma parte central desta. Isso também reflete o contínuo esforço discursivo da modernidade de silenciar o corpo ao privilegiar o âmbito do intelecto ou da alma, dependendo dos agentes sociais que são acionados em determinado contexto, reforçando essa dualidade entre o homem e o corpo. $\mathrm{O}$ acionamento do corpo enquanto mal necessário, algo que causa desconforto porque lembra o homem da falibilidade da carne e que só é "sentido" em casos específicos, socialmente determinados (LE BRETON, 2002[1990]), fica claro no caso da sexualidade ocidental do século XIX.

Em meio a esse caldo cultural do século XIX, surge o primeiro sistema de magia sexual na década de 1860 nos Estados Unidos por Paschal Beverly Randolph (DEVENEY apud HANEGRAAFF; KRIPAL, 2008; URBAN, 2006). Para ele, o sexo era a maior força da vida humana, mas se fosse mal utilizado, levaria à ruína moral e social. $\mathrm{O}$ sexo também era a chave para transformação social e para o fim da opressáo. $\mathrm{O}$ instinto sexual é identificado com o magnetismo, sendo a manipulação das forças elétricas e das leis de atração magnética cruciais para a obtenção de poder mágico, este atingido pelo orgasmo (physical love) com participação ativa do homem e da mulher ${ }^{12}$. Entretanto, o ato sexual deveria ser fundamentado no amor espiritual, não em luxúria. Isso porque a magia sexual era defendida somente para casais heterossexuais para fins de reprodução; caso contrário, era visto como sinal patológico e de decadência moral. Assim, esse primeiro sistema de magia sexual reafirma a perspectiva vitoriana acerca da sexualidade e do amor ligados ao casamento e o resto como patologia.

A mágicka, sistema produzido já no século XX, pode ser colocada enquanto síntese entre a magia ocidental e o Tantra, além de outras práticas orientais ${ }^{13}$. Essas práticas são ressignificadas para formarem o sistema de magia thelêmico. O sexo é vital neste caso porque é visto como a maior força existente e fonte suprema de poder mágico através do uso ritual do orgasmo e dos fluidos sexuais

\footnotetext{
${ }^{12}$ É interessante ressaltar as novas articulações possíveis entre magia e religião no século XIX, influenciadas pela ideia de Naturphilosophie, advinda do Romantismo Alemão (HANEGRAAFF, 2012).

13 Técnicas de meditação, Yoga, sistema de chakras e da Kundalini.
} 
combinados, já que eles permitiriam a obtenção do elixir da vida ${ }^{14}$ ou néctar dos deuses. São admitidas todas as formas de ato sexual, como a homossexual, heterossexual, anal, masturbatória etc. Todavia, a mágicka não se baseia somente em atos sexuais "explícitos": muitas práticas utilizam fluidos sexuais ou são consideradas sexuais porque são práticas de visualização ou meditação que têm por objetivo desenvolver magicamente as forças sexuais do magista.

De acordo com Hanegraaff e Kripal (2008), toda forma de magia sexual envolve uma polaridade: negativo e positivo; feminino e masculino ${ }^{15}$. A Besta (princípio masculino) e Babalon (princípio feminino) são os "operadores" da mágicka, pois são representações simbólicas da orientação ideológica da Thelema (DJURDJEVIC, 2013). Os símbolos da Prostituta Sagrada e da Besta, que são vistos como subversivos e, de certa forma, "malignos" por conta do arcabouço simbólico cristão, imbricado na sociedade ocidental da virada do século, são ressignificados e colocados como centro das práticas mágicas thelêmicas, lembrando-nos da ideia de carnavalesco de Bakhtin: "a condição social em que se reverte a ordem estabelecida por meio do livre exercício e da celebração do 'estrato inferior do corpo material'” (DJURDJEVIC, 2013, p. 64, tradução nossa) ${ }^{16}$.

É importante apreender a importância da dimensão material, sintetizada no corpo, que a magia sexual compreende a partir do século XX. Apesar da magia sexual existir há vários séculos, esta não estava sistematizada nem constituía centralidade das práticas religiosas das comunidades que a adotaram, mesmo no caso dos Borboritas. O corpo, dentro da cosmologia cristá, é um locus de sofrimento, de provação, porque é ele que pauta o destino do fiel: sua conduta em vida é voltada à vida após a morte - salvo ou condenado? -, tornando necessária a ideia de culpa ou pecado para orientar a existência. Todavia, o corpo cristáo é inviolável por ser a criação mais aperfeiçoada de Deus, já que o homem foi feito à sua imagem, e é ele que estabelece a relação da alma com o cosmos, com a criação divina. As técnicas corporais são dotadas de valores distintos dependendo dos sentidos da ação: se é para a glorificação de Deus e da criação, o corpo é tolerado; caso contrário, ele vira um receptáculo da alma que precisa ser estritamente controlado frente aos excessos da existência material para obtenção da

\footnotetext{
${ }^{14}$ A magia sexual, neste caso, é um processo alquímico e, de certa forma, científico. Assim como algum material misterioso é transformado em ouro através de uma manipulação específica do material, os fluidos sexuais são transformados em "Deus" por meio do ritual, que exige um método para sua eficácia (DJURDJEVIC, 2014b).

${ }_{15}$ Apesar dessa polaridade evidente, acredito que, em sistemas mágicos que não privilegiam somente práticas rituais heterossexuais, essa diferenciação entre feminino e masculino é borrada, haja vista as demandas das populações não-binárias, transexuais e genderfluid nesses sistemas.

16 "[...] the social condition brought about by reversing the established order through a free exercise and celebration of the "material bodily lower sratum"' (DJURDJEVIC, 2013, p.64).
} 
salvação. Apesar da dimensão corporal das práticas religiosas, elas tinham sentido contemplativo para tais comunidades. Já com Thelema, a coisa muda de figura: há uma sistematização da magia sexual, o que responde a uma tentativa de criar bases racionais, "científicas", para a magia. É a criação de uma teoria, de um método e de um modo empírico para testá-los. A centralidade e positivação do corpo são fundamentais para os novos contornos da magia sexual, uma vez que, através das práticas mágicas de cunho sexual - sendo o sexo algo que envolve interação entre corpos, não é metafísico -, o corpo se torna “outro". Isto porque os fluidos sexuais, em sua materialidade - isto é, quando expelidos pelo corpo durante o orgasmo -, são vistos como "Deus" (instinto sexual), antropomorfizados nas figuras de Babalon e da Besta.

Assim, a experiência resultante disso está totalmente atrelada às problemáticas sociais da virada do século XIX e XX - é intramundana, não uma fuga mística, uma vez que a reflexão sobre si a partir de uma prática mágica também traz a reflexão sobre o outro e sobre as formas pelas quais classificamos o mundo. Logo, o elemento "transgressivo" promovido por Thelema através da mágicka reflete a problemática da sexualidade ${ }^{17}$, oriunda principalmente do século XIX, em que se produz sobre sexo, mas náo se fala abertamente sobre ele, este estando moralmente circunscrito ao casamento e à boa conduta cristâ. Na verdade, esse posicionamento é um dispositivo de poder que controla e regula a vida social dentro de certos valores, o que nos coloca novamente a preeminência do homem enquanto pessoa metafísica (MAUSS, 2015[1950]) em detrimento da dimensão corporal - das sensaçóes e do contato com o outro como forma de constituição de si - por meio do silenciamento, mecanização e esvaziamento dos corpos (LE BRETON, 2002[1990]). Dito de outra forma, Thelema é uma ressignificação de elementos que já estavam presentes na sociedade ocidental a partir de novos valores, uma reinvenção da cultura (WAGNER, 2010[1975]), necessária a grupos cujo estar no mundo está em risco de se perder (DE MARTINO, 1977, 2004[1948], 2012 [1956]) em razão dos significados atribuídos às categorias de classificação da experiência perderem sentido frente às novas demandas e aos posicionamentos duais ligados ao corpo e ao homem enquanto entidades independentes, mas ligadas por um infortúnio, que é a corporalidade. Mas essa ressignificação de determinadas categorias, principalmente àquelas ligadas à sexualidade, só podem ser mais bem compreendidas se olharmos para as apropriaçóes

\footnotetext{
17 Elimina-se o caráter punitivo e pecaminoso da conduta individual por ser considerado restritivo à realização da Vontade. Todavia, o sexo e o prazer precisam estar "encaixados" na cosmovisão thelêmica, assentada na Vontade, o que ressignifica um corpo antes preso à repressão do prazer sexual, permitindo uma ideia a ser construída de liberdade sexual e até mesmo do próprio indivíduo.
} 
ocidentais feitas a partir do século XIX de discursos e práticas das religiōes orientais. Façamos uma breve discussão sobre o assunto na próxima seção.

\section{A importância do Oriente nos sistemas mágico-religiosos do Ocidente}

Em vistas de começarmos esta breve discussão acerca da influência do Oriente nas práticas esotéricas, é de interesse ressaltar que o Esoterismo tem como principal característica a apropriação e destradicionalização (HEELAS, 1993) de elementos provenientes de outros contextos significativos, rearticulando-os com base em novos valores e constituindo um novo conjunto prático-discursivo, utilizando-se desses elementos como forma de legitimação do que é novo. Essa tendência sincrética (DJURDJEVIC, 2014a) do Esoterismo pode ser traduzida na articulação particular feita por diversas comunidades religiosas entre o aparato prático-discursivo oriundo do Oriente e àquele do Ocidente, tendo como marco inicial a Sociedade Teosófica, fundada por Helena Blavatsky, em 1875 .

Todavia, o interesse suscitado pelo Oriente tem uma amplitude social maior do que somente no escopo religioso. Durante o século XIX, principalmente devido às políticas imperialistas promovidas pelas potências europeias na África e na Ásia, houve a intensa produção de uma literatura sobre tais regiôes, seja para informar aspectos políticos, econômicos e sociais destas, seja para traduzir textos locais ou para relatar as experiências de viajantes e estudiosos in loco. Como resultado dessa produção orientalista (SAID, 2007[1978]), uma relação de alteridade foi firmada entre Ocidente e Oriente, cuja principal problemática estava centrada, ora na exotização do outro, ora em sua degradaçãa ${ }^{18}$. $\mathrm{O}$ fascínio ocidental em relaçáo ao Oriente acentuou-se cada vez mais devido à publicação da tradução de livros provenientes da Índia, cujo conteúdo era geralmente sexualizado, além da publicação de livros demonstrando a depravação moral dos indianos e o atraso do país em relação à Europa, o que justificaria a dominação imperialista, indicando uma posição de superioridade do Ocidente frente ao Oriente.

Hugh Urban (2006) assinala que o Tantra foi alvo da apropriação orientalista a partir do século XIX justamente por conta dessa produção literária que recria o outro a partir de nossas próprias categorias de entendimento. Na pers-

\footnotetext{
${ }^{18}$ De acordo com Edward Said (2007[1978]), o Orientalismo se define como estilo de pensamento baseado na dicotomia entre Ocidente e Oriente; é um modo de abordagem do Oriente que tem como fundamento o lugar especial deste na experiência ocidental europeia; é um corpo teórico-prático dominado por relações de poder assimétricas traduzidas no Imperialismo; é uma forma de construção de si e do outro; um imaginário que não necessariamente possui realidade correspondente.
} 
pectiva do autor, o Tantra se define enquanto tradição de textos, ritos e práticas provenientes dos hindus, budistas e comunidades Jain do leste e do sul da Ásia a partir dos séculos IV e V d.C.. O Tantra asiático e sua apropriação ocidental possuem semelhanças no sentido de que ambos são formas de transgressão via práticas sexuais. Entretanto, a diferença reside na direção da transgressão: para o Ocidente, o Tantra era uma forma de subversão da ordem social cristá do século XIX, uma forma de liberação sexual. Urban observa que o Tantra asiático é uma tradição conservadora, pois não almeja transgredir ou contestar a ordem social vigente, apesar das rupturas da moral e das leis sexuais durante o rito - ele afirma a superioridade dos homens brâmanes ao colocar as mulheres como ferramentas na prática ritual, além de ser o homem que promove a união entre Shakti e Shiva, princípios feminino e masculino, e ainda bebe o néctar divino, ou amrita, que seria os fluidos sexuais combinados, considerados maior fonte de poder. Ademais, é uma tradição que possui regras bem estabelecidas e não abriga a concepção de uma criança como produto da operação ritual. Já o Tantra orientalista contribui para essa relação imperialista de poder traduzida na alteridade exotizada por meio da objetificação das mulheres indianas e da afirmação da Índia como país atrasado, uma vez que há proliferação de escritos pornográficos e uma perspectiva degradante do Tantra como algo impuro e perverso. No século XX, com a ascensão dos novos movimentos religiosos, a reinterpretação do Tantra é centrada no uso ritual do sexo, este ligado a práticas que permitiriam uma maior satisfação sexual a quem as pratica, além de uma confusão da literatura tântrica com a erótica, como o caso do Kama Sutra.

Urban ainda reflete sobre a importância da Ordo Templi Orientis - Ordem iniciática de cunho maçônico que é convertida à Lei de Thelema a partir de 1919, sendo liderada por Crowley até sua morte, em 1947 - na sistematização entre a tradição esotérica ocidental e o aparato prático-discursivo destradicionalizado do Oriente, através de seu líder na época, Theodor Reuss. O que é importante fixar sobre essa questáo é que o Tantra foi imediatamente conectado à magia sexual ocidental por se acreditar que eram comensuráveis ${ }^{19}$ (DJURDJEVIC, 2014a) e isso estava profundamente ligado à sacralização do ato sexual como forma de desestabilização das atitudes repressivas da sociedade ocidental da época e da criação de uma nova sociedade com base em uma visão liberal da sexualidade ${ }^{20}$ (URBAN, 2006).

\footnotetext{
${ }_{19}$ Penso na ideia de equivocidade tratada por Eduardo Viveiros de Castro (2009) na qual o compartilhamento de uma linguagem particular que explora conceitos sinônimos advindos de culturas distintas não exclui a possibilidade de que as pessoas envolvidas acreditem estar falando sobre a mesma coisa, mas trata-se de perspectivas distintas.

${ }^{20}$ É digno de nota que a concepção de sociedade liberal de Reuss admitia práticas homossexuais, mas à mulher era relegado o papel de mãe como algo a ser reverenciado. Há uma essencialização da mulher neste caso, o que revela uma postura conservadora de Reuss, diferentemente do que aparece na formulação teórica da mágicka de
} 
Se pensarmos na recepção e articulação de práticas orientais por Thelema, percebe-se que o sistema desenvolvido por Crowley ressignifica de forma considerável o Tantra e a Yoga, além das práticas de meditação budistas. A mágicka é fusão entre essas práticas orientais e o sistema de magia sexual, aportado pela Árvore da Vida cabalística e seu sistema de correlaçóes ${ }^{21}$. Como afirma Djurdjevic:

Isso demonstra que Crowley, ao reorganizar a Golden Dawn, se apoiou no que pode ser chamado de princípio do 'cosmopolitanismo oculto', que é dizer que o caminho thelêmico para aperfeiçoamento espiritual se baseia no amálgama de métodos de realização orientais e ocidentais. Isso foi uma inovação significativa, haja vista que as tradiçôes espirituais orientais quase não tinham importância na Golden Dawn original. (DJURDJEVIC, 2014a, p.110, tradução nossa ${ }^{22}$ ).

Assim, na perspectiva de Crowley, o treinamento da mente, típico das práticas de Yoga, era requisito necessário para o método mágicko. A Yoga foi reestruturada para se encaixar no modelo da Árvore da Vida e nos conceitos esotéricos ocidentais, fazendo com que a Yoga e a mágicka fossem aspectos diferentes do mesmo fenômeno (DJURDJEVIC, 2014a, p. 111).

Djurdjevic (2014b) demonstra a influência da Yoga tântrica dos Nath Siddhas - Ordem fundada no norte da Índia no período medieval -, praticantes do Hatha Yoga, na formulação da mágicka de Crowley, apesar da última ser uma inversão da primeira. Para os Nath Siddhas, os fluidos sexuais masculinos estão localizados na caixa craniana, onde está o elixir da imortalidade - amrita - em sua forma sutil. Caso o yogi ejacule, esse líquido é destruído, sendo esta a principal causa da doença, do envelhecimento e da morte. Assim, uma postura antissexual se faz presente, uma vez que a ejaculação prejudica o funcionamento do

Crowley, em que a mulher magicamente treinada era a Prostituta Sagrada, avatar feminino dos deuses. Digo apenas na questão teórica porque havia práticas altamente misóginas em Thelema, em que as Mulheres Escarlate eram marcadas a ferro e abandonadas quando não tinham mais utilidade ao magista.

${ }^{21}$ Sistema de correlações no qual o Esoterismo baseia seu aparato prático-discursivo, oriundo da cabala cristã proposta por Pico della Mirandola, em 1496. Também conhecida por Sephiroth. Consiste em dez emanações de Ain Soph (princípio imanifesto e ininteligível) na cabala cristã que carregam cada qual um princípio da existência, conectadas entre si por trinta e dois caminhos, divididas entre três pilares que se equilibram entre si e contendo uma pseudoesfera, Dä̈th, que permite a conexão entre a Árvore da Vida e a da Morte ou do Conhecimento, a Qliphoth. É entendida como um microcosmo do Universo (YATES, 1995[1964]).

22 "This shows that Crowley, in reorganizing the Golden Dawn, relied on what may be called the principle of "occult cosmopolitanism," which is to say that the Thelemic path to spiritual perfection rested upon the amalgamation of Eastern and Western methods of achievement. This was a significant innovation, since the Eastern spiritual traditions had almost no role in the original Golden Dawn" (DJURDJEVIC, 2014a, p.110). 
corpo. O autor ressalta que o celibato não é o objetivo, mas o processo de reversão do esperma (bindu) - ele deve sair dos órgãos genitais e voltar ao seu local de origem, o crânio. Para isso, utiliza-se a prática da Yoga, cujo objetivo é a uniâo das duas divindades - Shiva, que é o princípio masculino e tem como representantes o chakra da cabeça, o esperma e a Lua; e Shakti, o princípio feminino, representado pelo mênstruo, pelo chakra básico e pelo Sol -, liberando o yogi da dualidade fundamental, causadora de sofrimento e ignorância. Se a prática de sublimação for feita corretamente, o yogi se torna como um deus (godlike), pois seu corpo se torna divino, imortal e imbuído de poderes miraculosos.

Ainda segundo o autor, em linhas gerais, a título de comparação, na mágicka, apesar do interesse no potencial ambrosial dos fluidos sexuais, o esperma se move para baixo, é ejaculado e utilizado como elixir em sua forma material, além de ser santificado como forma de Eucaristia através da mistura deste com os fluidos sexuais vaginais. Neste caso, há a materialização do "espiritual”, uma vez que o esperma é forma análoga à consciência divina e representa a identidade essencial da pessoa, e a Eucaristia como representaçáo do corpo que se tornou outro. Ademais, a materialização da magia sexual também serve à criatividade artística, uma vez que a exaustão sexual enquanto método promovido pela mágicka engendraria estados alterados de consciência - vislumbres de uma realidade a ser construída a partir da criatividade.

Para concluirmos esta seção, gostaria de fazer um último comentário. A partir do que foi exposto acima, fica clara a importância do corpo nas práticas tântricas, mesmo que ele sirva como forma de sublimação, de fuga do mundo e da existência material. Sem a prática corporificada, o yogi não atinge seu objetivo porque é ela que reorienta a forma pela qual o yogi classifica a si, ao outro e ao que está em seu redor. Seu corpo é ressignificado; é tornado divinizado, não um mero receptáculo de Deus. Isso influencia seriamente o Esoterismo ocidental e sua preocupação com a materialidade do "sagrado" porque Deus não existe senão como representação meta-histórica do self ou consciência. A perspectiva monista da existência, em parte herdada pelo aparato prático-discursivo do Oriente, promove essa reorientação do corpo como algo positivo, algo necessário, já que o self não está separado da matéria e é através do condicionamento simbólico e prático do corpo por meio de um sistema mágico que se constroem formas de realidade que não as hegemônicas. A centralidade do sexo, não como prática contemplativa, mas como algo corporificado nos mostra a importância, no Ocidente, que o corpo toma como locus ordenador da experiência, dando ênfase à dimensão da práxis como detentora de uma capacidade de reordenação das categorias de organização do mundo (STENGERS, 2008), esta competên- 
cia não ficando restrita somente ao plano simbólico, da meta-história (LÉVISTRAUSS, 2012).

\section{Práticas de alteração de consciência}

No Esoterismo do século XX, as práticas de alteração de consciência foram cruciais para essa percepção da corporificação da experiência e de uma reorganização do mundo a partir do corpo através de novos valores associados a ele. Silvia Mancini (2018) afirma que as práticas psicocorporais com estados alterados de consciência ocupam papel central nas tradiçôes mágico-religiosas marginalizadas e transversais por conta de um modo particular de compreensão, concepção e manipulação da realidade, em que o problema da eficácia simbólica emerge. Os estados alterados de consciência se dão através do Eu dividido, dissociado e plural, formando o "outro" mediante psicotécnicas, e são cruciais na correção de "desordens" que afetam o corpo e o espírito dos indivíduos. Elas são importantes, de acordo com Mancini, porque a eficácia da magia se assenta em dispositivos ficcionais, que se encontram em outro regime de realidade, promovendo rupturas no estado de vigília, estimulando a imaginação e o desdobramento do Eu, este sendo o vetor real da eficácia. Isso porque os dispositivos ficcionais promovem um "fazer ativo", isto é, obriga seus agentes a agirem para retomarem o controle sobre si e sobre o mundo.

Em Thelema, praticar a mágicka pressupóe dissociação e pluralização do Eu para que a persona mágica se manifeste (MANCINI, 2018). Esta pode ser entendida como o self "divinizado", simbolizado pela Besta ou por Babalon. Cada thelemita possui um ou mais nomes ou personas mágicas, dependendo do direcionamento das práticas. Ademais, no caso dos thelemitas inseridos em ordens iniciáticas, cada um possui um nome mágico ao qual todos os outros membros se referem a ele, iniciado por Frater, para homens, e por Soror, para mulheres. A dissociação e pluralização do Eu pressupóe alteração de consciência porque, para os thelemitas, os deuses ${ }^{23}$ se encontram na região mais profunda do ser, o self, que pode ser entendido como o inconsciente, já que este é visto por eles como a fonte da consciência mágica, e não pode ser acessado no estado de vigília.

Em vários rituais, essa alteração de consciência é feita através do uso de bebidas alcoólicas e de substâncias psicoativas, tais como o éter, haxixe, morfina, cocaína e heroína (GRANT, 2015 [1972]). Crowley justificava sua utilização e

\footnotetext{
${ }^{23}$ Apesar da objetivação dos deuses enquanto realidade externa, em Thelema, a ideia de deus representa mais aspectos do self que devem ser aperfeiçoados via práticas mágicas do que uma entidade transcendente. Daí a célebre frase de Crowley: "There is no God but Man".
} 
suas próprias investigaçóes sobre o efeito dessas drogas a partir de um discurso científico a serviço da religião, já que, para ele, o domínio das substâncias poderia levar à aquisição de novos estados de consciência e a um aprofundamento da análise de caráter e de introspecção (GRANT, 2015 [1972]). As drogas, para ele, tinham relação com a Árvore da Vida, ou Sephiroth, em que as propriedades de determinadas substâncias condiziam com os princípios de determinada sephira. Todavia, o sexo tem grande importância nesse processo, uma vez que é através dele que os thelemitas podem experimentar outros modos de existir e de organizar a experiência: o orgasmo e os fluidos sexuais, principalmente quando consumidos, encarnam em sua materialidade "o poder dos deuses", ou seja, o sexo é uma técnica ou ação ritual que permite o contato com formas de realidade não acessíveis no estado de vigília e o retorno "seguro" a si. Utilizam-se avatares para a realização do sexo ritual, Babalon e Besta, porque entende-se que o próprio sexo é um alterador de consciência, já que apenas os magicamente treinados podem realizar tais ritos sexuais. Para Crowley, é através da exaustão sexual, pensada enquanto método, que se chegaria aos estados mais alterados de consciência, já que o uso constante do sexo permitiria a morte do Ego, a despossessão de si necessária ao fazer ativo capaz de construir realidades possíveis que assegurariam a retomada de si e do mundo (MANCINI, 2018). Assim, apreende-se que, por conta da assunção dos avatares da Besta e de Babalon, haja dissolução, pluralização e mesmo certa "confusão" entre a personalidade individual e as personas mágicas encarnadas na situação ritual. Entretanto, o sucesso da operação mágica depende disso.

A Missa Gnóstica é interessante de ser pensada como exercício ortoprático e ethopoiético ${ }^{24}$, já que ela ressignifica todo um aparato simbólico advindo do Cristianismo. É um rito mais longo e o principal praticado na Ordo Templi Orientis. Consiste em uma forma de interação erótica, sobretudo, entre o Cálice e a Lança, representados, respectivamente, pela Sacerdotisa e pelo Sacerdote ${ }^{25}$. Há vários momentos na Missa, com a proclamação de trechos do Livro da Lei e com utilização de linguagem verbal e gestual entre as personas mágicas, além de percorrerem um trajeto específico dentro do templo. É importante perceber que, à medida que o rito avança, o Sacerdote e a Sacerdotisa entram em uma espécie de "êxtase" religioso crescente por conta da troca de palavras e de gestos e, após a Eucaristia, que consiste no consumo, com vinho, de um bolinho que con-

\footnotetext{
${ }^{24}$ Isto é, práticas que transformam ativamente o mundo e o sujeito através de técnicas que atravessam o corpo, importando um termo foucaultiano. (MANCINI, 2018).

${ }^{25}$ Há outras personagens rituais: o Diácono, as Crianças e a Congregação, cada qual com suas funções, mas foge ao escopo deste artigo especificá-las.
} 
tém fluidos sexuais femininos e masculinos, segue-se um momento de aparente exaustão. Neste caso, a insinuação sexual, fortemente presente no texto da Missa e em seus gestuais, funciona como alterador de consciência, além da assunção dos avatares de Sacerdote e Sacerdotisa por thelemitas previamente selecionados. Quando o ápice do ritual acontece, com a comunhão, o corpo é ressignificado com as implicaçóes axiológicas do que é o "sagrado" - isto é, o homem na sua corporalidade -, e o próprio rito força o participante a voltar a si, pois o objetivo ritual já foi atingido.

\section{Uma perspectiva demartiniana sobre magia sexual thelêmica}

Gostaríamos de apontar para um caminho teórico-metodológico que acreditamos ser profícuo no entendimento dos novos movimentos religiosos no Ocidente a partir do final do século XIX: àquele proposto por Ernesto de Martino (1977, 2004[1948], 2012 [1956]). Apesar de não tratar especificamente sobre a ideia de corpo, reflete acerca da noção de "presença" - devedora do Dasein heideggeriano - e sua relação dialética para com a experiência religiosa, entendida em termos de "dispositivo mítico-ritual". Para o antropólogo, o ethos humano fundamental se assenta na potência moral, que é o poder dialético em que o homem classifica a experiência e as coisas por meio de juízos de valor. A presença cultural, ideia de "estar aî", se dá por essa "energia categorizadora" que está inserida na história e, por conseguinte, na sociedade, pois a sociedade equivale à história para o autor, ambas significando o modo de organização coletiva que visa ao domínio técnico da natureza, que se refaz ad infinitum por conta desse processo dialético característico da dimensão histórica. De Martino (2004 [1948]) assinala, em El Mundo Mágico, que, para o Ocidente, a garantia da presença no mundo - ou seja, o processo de objetivação da realidade por parte do sujeito- é algo dado a priori. Mas no que autor denomina como "mundo mágico", uma instabilidade coletiva é a característica marcante da presença, causando precariedade existencial. A presença garante a manutenção do sujeito na dimensão da cultura; quando entra em risco de instabilidade, há perigo de retorno a uma condição de natureza, não-cultura. Para o autor, o mundo mágico expressa um drama cultural histórico (o "drama histórico do mundo mágico") em que o "estar-no-mundo" é uma realidade condenda - que precisa ser construída-, pois está permanentemente exposta ao risco de perda de presença, de alienação do ser. Apesar de De Martino apenas assinalar o risco de "perder a presença no mundo" como problema cultural das sociedades tradicionais, em La Fine del Mondo (DE MARTINO, 1977), ele afirma, por meio da análise dos 
apocalipses culturais, que este drama existencial é inerente à condição humana, ou seja, compreende também a sociedade ocidental. Assim, a própria noção de realidade deve ser repensada enquanto categoria classificadora, já que o mundo mágico opera em um regime de realidade distinto do ocidental.

O drama existencial mágico se constitui em duas etapas, em uma polaridade dramática: a crise da presença, cujo risco de "não estar-no-mundo" é expresso em forma de angústia porque a presença em si é frágil, e o resgate cultural da presença, que consiste na criação de formas culturais definidas, geralmente com o recurso ao dispositivo mítico-ritual, a partir da noção de "de-historificação institucionalizada", ou seja, um "regime protegido" em que a "presença doente" é reconduzida ao mundo dos valores culturais mediante o simbolismo mítico-ritual (DE MARTINO, 2012 [1956]). O drama ocorre em momentos críticos da existência, quando se exige um esforço muito grande da presença, demandando uma reparação equilibradora. E a eficácia salvadora do resgate cultural é justamente dar ordem ao caos de forma culturalmente relevante ao impedir o ato de dissoluçáo completa do Eu.

O caso de Thelema pode ser enquadrado dentro da formulação teórico-metodológica demartiniana, uma vez que o aparecimento de sistemas de magia sexual, levando em consideração a centralidade do sexo na prática mágicka, pode ser entendido como uma solução cultural para uma presença em crise, proporcionada pelas problemáticas oriundas da sociedade vitoriana do século XIX, àquela apoiada em um recurso ao dispositivo mítico-ritual. A existência não faz sentido a partir do sistema axiológico reproduzido socialmente e o indivíduo precisa de um espaço institucionalizado, como a religiáo, para resolver a crise que o assola - neste caso, a causa da sua angústia reside nas questóes da virada do século - por meio de sua exacerbação. O elemento ritual transgressivo em Thelema pode ser entendido como forma de exacerbação de uma crise de presença, na qual a sexualidade não é aceita a não ser dentro das prescriçóes sociais adscritas ao casamento e à procriação, pelo menos se levarmos em consideração que o Esoterismo atinge as camadas médias da sociedade, principalmente as mais intelectualizadas, alvos desse controle. O sexo é o valor posto em jogo nesta situação. Ele é aplicado em todas as dimensóes da vida do adepto, sendo este o próprio objeto de culto do thelemita, mas é ressignificado através da práxi ${ }^{26}$ por meio do rito - esse espaço de-historificado no qual o sexo é levado ao extremo,

\footnotetext{
${ }^{26}$ Pode-se pensar aqui, extrapolando o aporte demartiniano, a partir da Antropologia Hermenêutica proposta por Clifford Geertz (1989), em que a cultura é uma teia de significações atualizada pela práxis, o que nos coloca a questão da elasticidade das cosmologias frente à vida prática por conta dos conflitos decorrentes entre instituições sociais, daí seu caráter de dramaticidade.
} 
com diversas modalidades, retirado do contexto moralizante da época. O sexo é colocado como o motor da vida, como a conexão entre o homem e o "sagrado" 27 , que é uma dualidade aparente. Ele força o adepto a olhar para o próprio corpo, este sendo ressignificado através de um novo conjunto valorativo, que opera tanto no nível do simbólico quanto no da práxis.

O risco de perda do mundo, pensado por Le Breton (2002[1990]) como a desconexão no nível ontológico com o cosmos, com o tecido social, promovido pelo individualismo, força o indivíduo, reduzido a uma máquina que aporta uma subjetividade, a tratar o corpo como um duplo, um alter ego, no sentido de que o corpo é identificado com a pessoa e se torna a fronteira da subjetividade e da diferença. A dualidade formativa da modernidade ganha outra figura, segundo o autor, quando passa por uma mudança nos sentidos atribuídos à ação: a da positivação e da estetização do corpo, que fazem o indivíduo cuidar de si e perceber o corpo através da dimensão da experiência. Todavia, esse "dualismo personalizado” (LE BRETON (2002[1990]) reforça o caráter maquinário do corpo, pois o aperfeiçoamento deste se torna sinônimo de um aperfeiçoamento do Eu. A categoria "sexo" já existia anteriormente, mas sua articulação com um dispositivo mítico-ritual, no caso a Lei de Thelema e a mágicka, possibilita ao adepto uma nova postura frente à vida, que o permitem fazer parte de uma sociedade, desde que ele sempre mobilize tal conjunto de valores dentro do plano ritual porque é por meio da repetição do rito que aquele se cristaliza na comunidade e no indivíduo. É uma forma de se amenizar a angústia existencial proveniente de uma postura ontológica ocidental que nega outras formas de ser e de estar no mundo.

\section{Considerações finais}

À guisa de conclusão, fica claro que a magia sexual no Ocidente opera no sentido de repensar uma forma de realidade que é percebida como dada por nós por meio do uso dos estados alterados de consciência, colocando o sexo como dispositivo responsável, de um lado, por dissociar o Eu e, de outro, por forçar o indivíduo a tomar o controle de si e do mundo. A realidade, por ser algo a ser construído, depende das práticas de alteração de consciência para desmembrar e rearticular o mundo dentro de categorias cujos valores são repensados, reinventados culturalmente (WAGNER, 2010[1975]) porque precisam ser constantemente afirmados através de uma prática ritual institucionalizada.

\footnotetext{
${ }^{27}$ Se o sagrado é a própria corporalidade do adepto, aquele não pode ser apreendido de forma essencialista, uma vez que, se o corpo é continuamente construído e ressignificado, os sentidos atribuídos ao sagrado também os são.
} 
E o corpo não passa despercebido: é através dele que a reinvenção da cultura (WAGNER, 2010[1975]) é sentida porque o corpo articula sentidos e significados, e a noção de pessoa é constantemente transformada porque o corpo é performado (MALUF, 2001). Mais do que a pluralização do Eu, há a multiplicidade do corpo: ele recebe outras camadas de significação e outras formas possíveis de existência. Assim, a magia sexual no Ocidente do século XX ressalta "a centralidade da experiência corporal, o foco no corpo como valor e núcleo dramático de determinados enredos sociais e a atribuição de um tipo de agência especial ao corpo" (MALUF, 2001, p.96).

Como última reflexão, coloca-se a importância do entendimento da magia sexual no Esoterismo do século XX como produto das tensôes e demandas sociopolíticas do final do século XIX - principalmente àquelas ligadas à sexualidade e aos problemas derivados do individualismo crescente, que culminam nos movimentos contraculturais da década de 1960, mobilizando figuras como o Crowley enquanto modelos de uma nova conduta frente à vida, uma transgressão necessária, e uma atenção voltada ao indivíduo e à subjetividade -, além de um esforço por parte dos novos movimentos religiosos de legitimar a magia por meio de um discurso científico, típico de um processo de racionalização das esferas de ação. Assim, a ressignificação do sexo nos planos simbólico e prático permite que uma nova concepção de corpo emerja, relativizando seu caráter punitivo e negador de si a partir do qual foi construído historicamente devido à cristalização de uma moral cristã baseada no pecado e de dualismos - mesmo aparentes- que permearam a modernidade, tal como "espírito X matéria" (LATOUR, 1994), colocando o "corpo como símbolo, veículo e lugar da nova ordem social" (MARTINS apud CAROZZI et al., 1999). O reaparecimento de práticas, mesmo de forma marginalizada, que reinserem no âmbito público a dimensão do asqueroso, que repensam a ideia de corpo como resíduo - este agora subordinado discursivamente à dimensão da vontade e, por consequência, da autonomia individual - , fazem-nos pensar se somos tão "civilizados" quanto queremos $\operatorname{parecer}^{28}$ (ELIAS, 1990). A própria marginalização e repulsa social em relação à magia sexual já demonstram a expressão de uma relação negativa de alteridade dentro da própria sociedade ocidental, mas é importantíssima para a apreensão

\footnotetext{
${ }^{28}$ Não se quer dizer aqui que a questão do autocontrole individual caiu por terra com as práticas de magia sexual, uma vez que os próprios sistemas desenvolvidos na época atendem ao problema do indivíduo - são religiosidades do self (HEELAS, 1993) - porque é uma forma de orientar o corpo frente a uma individualização extremada através da racionalização da magia, e isso exige autocontrole. A transgressão é ritual, existe um espaço institucionalizado para que ela aconteça. Por mais que a magia sexual tenha sido uma centelha que possibilitou as revoluções sexuais das décadas de 1960 e 1970, o sexo ainda é alvo de tabu e prescrições na sociedade ocidental, além de continuar como atividade íntima, típica da esfera privada.
} 
contemporânea do corpo no Ocidente: o corpo-máquina borrado ritualmente e o corpo-máquina como alter ego do homem (LE BRETON, 2002[1990]). A magia continua sendo um problema do outro, mas, desta vez, esse "outro" não está distante no espaço-tempo - é o outro no mesmo, é tornar-se outro em si -, o que nos coloca a pluralidade de mundos possíveis a serem construídos dentro da sociedade ocidental - realidades condendas (DE MARTINO, 2004[1948]).

\section{REFERÊNCIAS}

CAROZZI, M. J. et al. (org.). A Nova Era no Mercosul. Petrópolis: Vozes, 1999.

CROWLEY, A. O Livro da Lei. São Paulo: Chave, 2017 [1904].

CROWLEY, A. Magick in Theory and Practice. In: CROWLEY, A. Magick (Book IV). Portugal: Hermetic Library, 2017. Disponível em: https://hermetic.com/_ detail/pt/crowley/book-4/hermetic-sections-crowley-magick-em-teoria-e-pratica. png? id=pt\%3Acrowley\%3Abook-4\%3Aaba3. Acesso em: 20 jan. 2021.

DE MARTINO, E. Crisis of Presence and Religious Reintegration. Prefaced and translated by Tobia Farnetti and Charles Stewart. HAU: Journal of Ethnographic Theory, London, v. 2, n. 2, p. 431-450, 2012 [1956].

DE MARTINO, E. El Mundo Mágico. Buenos Aires: Libros de la Araucaria, 2004 [1948].

DE MARTINO, E. La Fine del Mondo: contributo all'analisi deli apocalissi culturali. Torino: Giulio Einaudi Editore, 1977.

DJURDJEVIC, G. India and the Occult: the influence of South Asian spirituality on Modern Western Occultism. New York: Palgrave Macmillan, $2014 \mathrm{a}$.

DJURDJEVIC, G. Solve et Coagula: atitudes towards the ambrosial aspects of human seed in certain yogic traditions and in the sexual magick of Aleister Crowley. In: DJURDJEVIC, G. India and the Occult: the influence of South Asian spirituality on Modern Western Occultism. New York: Palgrave Macmillan, 2014b. p.61-72.

DJURDJEVIC, G. Our Lady Babalon and her Cup of Fornications: approaches to a Thelemic Goddess. Journal Of Occult Arts, Letters And Experience, Seattle, p. 55-65, 22 out. 2013.

DJURDJEVIC, G. The birth of the new aeon: magick and mysticism of Thelema from the perspective of post-modern theology. 2008. 
ELIAS, N. O processo civilizador: uma história dos costumes. Sáo Paulo: Zahar, 1990. v. 1.

FOUCAULT, M. História da Sexualidade: Vontade de Saber. São Paulo: Paz e Terra, 2015 [1976]. v.1.

GEERTZ, C. Por uma descrição densa: por uma teoria interpretativa da cultura. In: GEERTZ, C. A interpretaçáo das culturas. Rio de Janeiro: Guanabara Koogan, 1989. p. 13-41.

GRANT, K. O Renascer da Magia. Rio de Janeiro: Penumbra Livros, 2015 [1972].

GRANT, K. Outside the circles of time. Londres: Frederick Muller, 1980.

GUERRIERO, S. et al. Os Componentes Constitutivos da Nova Era: A Formação de um Novo Ethos. Rever, São Paulo, v. 16, n. 2, p.10-30, maio 2016.

HANEGRAAFF, W. J. Esotericism and the Academy. New York: Cambridge University Press, 2012.

HANEGRAAFF, W. J.; KRIPAL, J. J. Hidden Intercourse: eros and sexuality in the History of Western Esotericism. Boston: Brill, 2008.

HEELAS, P. The new age in cultural context: the premodern, the modern and the postmodern. Religion, Lancaster, n. 23, 1993.

LATOUR, B. Jamais fomos modernos. Rio de Janeiro: Ed. 34, 1994.

LE BRETON, D. Antropologia del cuerpo y modernidad. Buenos Aires: Ediciones Nueva Visión, 2002[1990].

LÉVI-STRAUSS, C. Antropologia Estrutural. São Paulo: Cosac \& Naify, 2012. v.1.

MALUF, S. W. Corpo e corporalidade nas culturas contemporâneas: abordagens antropológicas. Esboços: histórias em contextos globais, Florianópolis, v. 9, n. 9, p. 87-101, 2001.

MANCINI, S. La religión como técnica: reflexiones histórico-religiosas sobre la eficacia de algunas prácticas psicocorporales que utilizan la disociación psíquica en contextos rituales. In: DI STEFANO, R.; SILVA, A. R. C. da. (org.). História das religióes em perspectiva: desafios conceituais, diálogos interdisciplinares e questóes metodológicas. Curitiba: Prismas, 2018. p. 27-62.

MAUSS, M. Uma categoria do Espírito humano: a noção de pessoa, a de 'Eu'. In: MAUSS, M. Sociologia e Antropologia. São Paulo: Cosac \& Naify, 2015[1950]. p. 365-396. 
SAID, E. Orientalismo: o Oriente como invenção do Ocidente. São Paulo: Companhia das Letras, 2007[1978].

STENGERS, I. Pensar a partir de la cuestión de la eficácia. In: MANCINI, S. (org.). La fabricación del psiquismo: práticas rituales em el cruce de las ciências humanas y las ciências de la vida. Buenos Aires: Libros de la Araucaria, 2008. p. 269-284.

THOMAS, K. Religion and the Decline of Magic. London: Penguin Books, 1971.

URBAN, H. B. Magia Sexualis: sex, magic \& liberation in modern western esotericism. Los Angeles: University of California Press, 2006.

VAN DEN BROEK, R. et al. Gnosis and Hermeticism from Antiquity to Modern Times. New York: State University of New York Press, 1998.

VIVEIROS DE CASTRO, E. Metafísicas Canibais. São Paulo: Ubu editora e n-1 ediçôes, 2009.

WAGNER, R. A invençáo da cultura. São Paulo: Cosac \& Naify, 2010 [1975].

WEBER, M. A ética protestante e o espírito do capitalismo. São Paulo: Companhia das Letras, 2016 [1920].

WEEKS, J. Sex, politics and Society: the regulation of sexuality since 1800 . New York: Routledge, 2012[1981].

YATES, F. Giordano Bruno e a Tradiçáo Hermética. São Paulo: Cultrix, 1995 [1964].

Recebido em: 13 de setembro de 2020

Aprovado em: 20 de outubro de 2020 